\title{
Çevreden Kaynaklanan Göçün Boyutu: Gelişmiş ve Gelişmekte Olan Ülkeler Üzerine Bir Çalışma
}

* Sorumlu Yazar / Corresponding Author: Nehir Varol Ankara Üniversitesi Beypazarı Meslek Yüksek Okulu Acil Durum ve Afet Yönetimi Programı 06730 Beypazarı, Ankara / TÜRKIYE E-posta: nvarol@ankara.edu.tr

\author{
Md Moynul Ahsan ${ }^{1} \odot$, Nehir Varol ${ }^{2 *} \odot$ \\ ' Dr. Öğr. Üyesi | Ankara Üniversitesi, Uygulamalı Bilimler Fakültesi, Gayrimenkul Geliştirme ve Yönetimi \\ Bölümü, Ankara/TÜRKiYE \\ ${ }^{2}$ Dr. Öğr. Üyesi | Ankara Üniversitesi, Beypazarı Meslek Yüksekokulu, Acil Durum ve Afet Yönetimi \\ Programı, Ankara/TÜRKIYE
}

Alındı/Received: 25 Şubat / February 2020 Düzeltildi/Revised: 22 Nisan / April 2020 Kabul/Accepted: 5 Mayıs / May 2020 Yayımlandı/Published: 29 Haziran / June 2020

\section{$\ddot{O} z$}

Günümüzde iklim değişikliğinin etkileri sonucu tetiklenen çevresel göçler, yoğun olarak yaşanmasına rağmen, uluslararası politikalar açısından hala tartışmalı bir konu olmaya devam etmektedir. Dünyada her 45 kişiden birinin 2050 yllına kadar iklim değişikliği nedeniyle yer değiştirme zorunda kalacağı tahmin edilmektedir. Dünya Bankası'nın son yayımlanan raporunda, Sahra altı Afrika, Güney Asya ve Latin Amerika'daki 143 milyondan fazla (yaklaşık \%2,8) vatandaşın 2050 yllına kadar iklim değişikliğinin etkilerinden kaçmak için kendi ülkeleri içerisinde yer değiştirmek zorunda kalacakları belirtilmektedir. Bu durum bile iklim değișikliklerinden kaynaklanan göçün küresel bağlamda bir problem haline geldiğinin bir göstergesidir. Ancak halen, çevre kaynaklı göçmenleri korumak için somut uluslararası bir yasa yoktur. Gelişmekte olan ve gelişmiş ülkeler bu problemden dolayı büyük zorluklarla karşı karşıya olduğundan dolayı, çevresel afetlerin etkilerine karşı "sıcak noktaların" kııllganlıklarını azaltmak ve riski yönetmek için acil, kapsamlı bir çerçeve planı geliştirilmelidir. Bu makale ile sorunun ne kadar büyük olduğu ortaya koyulmakta, gelişmiş ve az gelişmiş ülkelerde çevrekaynaklı göçmenlerin risklerini, sorunlarını azaltmada uluslararası sorumluluğun önemine vurgu yapılmaktadır.

Anahtar Sözcükler: Çevresel göç, uluslararası çevresel sorumluluk, iklim değişikliğine uyumu

\section{Giriş}

Göç, zorunlu veya gönüllü olarak, yaşanılan yerin geçici ya da kalıcı olarak terk edilmesi olup, genel bağlamda ekonomi, savaş, terör, çevre ve afet gibi faktörlerle tetiklenebilmektedir (Varol and Gültekin, 2016). İklim değişikliklerinin etkileri ile hızlanan çevre kaynaklı göçün ortaya çıkmasının da siyasal, sosyal ve ekonomik pek çok nedeni vardır.

Araştırmacılar, çevre göçmenleri için özel bir tanım bulunmadığını iddia etmektedirler. "Çevresel göçmen”, "iklimsel göçmen” terimleri çeşitli bilim insanları

\section{Magnitude of Environmentally Induced Migration: A Study} on Developed and Developing Countries

\section{Abstract}

Although the environmental migrations has become a triggering factor nowadays as the result of climate change effects, the issue of migration is still controversial for the international poltics. It is estimated that by 2050 one in every 45 people in the world will be displaced by the impact of climate change. More than 143 million (around 2,8\%) internal climate migrants from Sub-Saharan Africa, South Asia and Latin America could be forced to move within their own countries to escape the slow-onset disasters by the 2050. Therefore, it becomes a responsibility at the international level, however there is no concrete international law to protect the environmentally induced migrants. As both developed and developing countries are facing huge challenges they should, therefore, portray its urgency, depth and coordinated framework for addressing challenges with "hotspot"s to reduce their vulnerability to the impacts of environmental disasters and manage the risks. This paper tries to explain how big the problem is, what international liability lies on developed and developing countries in reducing risk, and the problems of environmentally induced migrants.

Key Words: Environmental migration, international environmental responsibility, adaptation to climate change

tarafindan farklı amaçlarla kullanılan terimlerdendir. IOM "çevresel göçmenleri”" şu şekilde tanımlamıştır: "yaşamlarının veya yaşam koşullarının çevredeki ani veya yavaş değişimin zorlayıcı nedenlerinden dolayı olumsuz etkilenmesi ile yaşam alanlarını geçici veya kalıcı olarak kendi ülkeleri içerisinde kalarak ya da yurt dişına çıkmak suretiyle terk etmeye zorlanan ya da kendisi tercih eden kişiler ve/veya gruplardır" (IOM 2007, s. 1-2; IOM, 2011, s. 33). Bu kavram "zorunlu" ve "gönüllü” göçü kapsamaktadır. İnsanlar çoğunlukla, bu yer değiştirmeye/göçe gönüllü olmadı̆̆ı halde, 
yine de farklı gerçekçi seçenekler arasında seçim yapma durumunda kalabilmektedir (UNISDR, 2018).

Topluluklar, sel, şiddetli kasırga, yıkıcı deprem, hızlı nehir erozyonu, kuraklık, çölleşme, ormansızlaşma ve diğer çevresel tehlikelerin yanı sıra, hızlı nüfus artışı, yoksulluk ve yönetimlerdeki zayıflıklar gibi sorunlarla sürekli yüz yüze kalmaktadır. Bu bakımdan çevresel olaylar ve ilişkili sorunların etkileri, çoğu zaman insanları kendi arazilerinde veya topluluklarında yaşamlarını devam ettirme konusunda sikıntıya sokmakta, ülke içerisinde veya ülke dışında barınma alternatifleri bulma konusunda çaresiz bırakmaktadır (Leutz, 2013). Uluslararası örgütlerin, devlet kurumlarının ve sivil toplum kuruluşlarının bu sorumluluğu üstlenmeleri gerekmektedir (Ahsan, 2017). Özellikle, uluslararas1 örgütler, çevresel afetler karşısında kırılganlıkları azaltma ve çevresel süreçlerin gelişimindeki zorlukları gidermenin (Council of Europe, 2008) yanı sıra öncelikli olarak, "sicak nokta" ülkelerini veya bölgelerini ele alarak, bu konuda koordinasyonu hızla gerçekleştirmelidir (UNHCR, 2017). Devlet kurumlar1 ise bu sorundaki kaçınılmaz rolünü kabul etmeli ve öncelemelidir (Ahsan, 2017). Birleşmiş Milletler de dönem dönem yaptığ1 deklerasyonlarda (İnsani Yardım Koordinasyon Ofisi'nin Ülke İçinde Yerinden Edilmenin Temel İlkeleri, 1998, Afrika'daki Ülke İçi Yerinden Edilmiş Kişilere Yardım ve Koruma Sağlamaya Yönelik Afrika Birliği Sözleşmesi (Kampala Sözleşmesi) 2009, Yarımada İlkeleri, 2013, Sendai Afet Risklerini Azaltma Çerçevesi 2015 - 2030), afet risklerini azaltma konusunda en önemli rolün devlette olduğunu vurgulamaktadır (UNOCHA, 2004; UNISDR, 2015; McAdam, 2016, s. 1525).

Çevreden kaynaklanan göçün yönetilmesi gelişmekte olan ülkelerdeki politika yapıcılar için zorlu bir süreç oluşturmaktadır. Bazen göç yaşamın ve ekosistemin riskini azaltmaya, gelir çeşitliliğine katkıda bulunmaya ve iklim değişikliğinin olumsuz etkileriyle başa çıkmak için toplumun kapasitesini arttırmaya yardımc1 olabilecek bir araç haline gelebilir (IOM, 2008a). Öte yandan, finansal kapasitesi güçlü olan, gelişmiş ülkeler, yeterli bütçe ve güçlü bir altyapıya sahip oldukları için, çevresel mağdurlara yeterli ulusal projeler, programlar ve uygulamalar sunabilmektedirler. Bu durumda çevresel afetin koordinasyonu ve adaptasyonu da hızlı bir şekilde gerçekleşebilir. $\mathrm{Bu}$ makalede de, kırılgan ülkelerde çevre/iklim kaynaklı göçmenlerin riskleri orta koyulmuş ve bu risklerin azaltılmasında uluslararası sorumluluğun ne kadar önemli olduğu vurgulanmıştır.

\section{Araştırma yöntemi}

$\mathrm{Bu}$ çalışmada, ulusal ve uluslararası ve düzeyde literatürdeki çevreden kaynaklanan göç konusunda yapılan çalışmalar incelenmiştir. İncelemede, çevresel göçmen sorunlarını tanımlamak için niceliksel veriler dikkate alınmıştır. İkincil kaynak olarak, bu konuda çalışmalar yapan Birleşmiş Milletler Afet Riskinin Azaltılmas1 Uluslararas1 Stratejisi Platformu (UNISDR), Birleşmiş Milletler Çevre Programı (UNEP), Birleşmiş Milletler Mülteciler Yüksek Komiserliği (UNHCR), Uluslararası Göç Örgütü (IOM), Dünya Bankası ve İç Göç İzleme Merkezi'nin (IDMC) raporları incelenmiştir; çünkü kamu kurumlarının çoğunda birincil araştırmalar konusunda eksiklikler bulunmaktadır. Uluslararas1 sivil toplum kuruluşları (STK) ise yoksulluk ve göç konusunda kanıta dayalı bir çok araştrma ve proje yapmaktadırlar (Hayman vd., 2016). Bu tür kanita dayalı araştırmalar aynı zamanda hükümetlerin politika ve uygulamalarını da olumlu yönde etkilemektedir. Bu nedenle, bu inceleme makalesinde, uluslararası STK'lar tarafindan yapılan araştırma ve yayınlar temel alınmıştır.

\section{Tartışma}

İnsanlar hem gelişmiş hem de gelişmekte olan ülkelerden, aşırı hava olaylarıyla tetiklenen problemler yüzünden yerlerinden olmaktadır. Tarihsel kayıtlara göre, gelişmiş ülkelerde çı̆̆, tropikal siklon, deprem, açlık, sel, heyelan, kasırga gibi afetlerin; gelişmekte olan ülkelerde ise sicaklık dalgası, firtına, tsunami, orman yangınları gibi afetlerin en sık yaşanan afetler olduğu görülmektedir. Antropolojik ve arkeolojik bulgular geçmişte de büyük göçlerin varlı̆̆ını ortaya koymaktadır. Örneğin, Indus Vadisi'nde 200 yll süren kuraklık, şu anda Pakistan'da bulunan Harrapan Topluluğu'nun kent merkezlerini terk etmesine neden olmuştur (Waldinger ve Fankhauser, 2015). Çölleşme nedeniyle Sahel Bölgesi'nden Bat1 Afrika'nın nemli iklimine (yaklaşık 9000 ila 6000 yıl önce Afrika bölgesi çok daha nemliydi; Sahra, göle ve yeşil alana sahipti) göç edilmiştir (Waldinger ve Fankhauser, 2015). Yağmurun azalmas1, Sahra altı Afrika'daki yağmurla beslenen tarım arazilerinin zarar görmesi ve buna bağlı olarak ekonominin bozulması göçü tetiklemiştir.

1970-2000 dönemi boyunca, dış göçü iki katına çıkmıs olan 20 ülke "Kirllgan 20 grubu" olarak nitelendirilmektedir. 1980'de neoliberalizasyon döneminin başlangıcindan sonra, bu ülkelerden gelen göçmenlerin sayısı daha keskin bir şekilde artmıştır. 1960-2000 döneminde gelişmiş ülkeler ve gelişmekte olan küçük ada ülkeleri, iklim kaynaklı afetlerin etkileriyle yüz yüze kalmıştır. İklim kaynaklı göç, mutlak ve göreli büyüklükte artmıştır. Kırllgan 20 ülkelerinden, en az gelişmiş ülkelerden ve gelişmekte olan küçük ada ülkelerinden göç akımlarındakı artış eğilimi, göç eden toplam kişi verileriyle de (ev sahibi ülkedeki göçmen sayısına göre) doğrulanmaktadır.

2000 yllından sonra, örneğin 2003 Avrupa sicak hava dalgasi, 2004 Hint Okyanusu depremi ve tsunamisi, 2005 Katrina ve Rita Kasırgalar1, 2005 Kashmir 
Tablo 1. 2011-2018 yılları arası çevresel etki ve göç durumunu gösteren küresel riskler (World Economic Forum, 2018'den uyarlanmıştır).

\begin{tabular}{|c|c|c|c|}
\hline Yillar & & Riskler & \\
\hline 2011 & İklim değişikliği & & \\
\hline 2012 & Su temini krizleri & & \\
\hline 2013 & Su temini krizleri & $\begin{array}{l}\text { İklim değişikliğinin etkilerinin } \\
\text { azaltılmasında ve uyumda sorun }\end{array}$ & \\
\hline 2014 & İklim değişikliği & Su krizleri & \\
\hline 2015 & $\begin{array}{l}\text { İklim değişikliğinin etkilerinin } \\
\text { azaltılmasında ve uyumda sorun }\end{array}$ & & \\
\hline 2016 & $\begin{array}{l}\text { İklim değişikliğinin etkilerinin } \\
\text { azaltılmasında ve uyumda sorun }\end{array}$ & Büyük ölçekli istemsiz göç & \\
\hline 2017 & Aşırı hava olayları & Büyük doğal afetler & $\begin{array}{l}\text { İklim değişikliğinin etkilerinin } \\
\text { azaltılmasında ve uyumda sorun }\end{array}$ \\
\hline 2018 & Aşırı hava olayları & Doğal afetler & $\begin{array}{l}\text { İklim değişikliğinin etkilerinin } \\
\text { azaltılmasında ve uyumda sorun }\end{array}$ \\
\hline
\end{tabular}

Depremi, 2006 Avrupa sicak hava dalgas1, 2007 Sidr kasırgas1, 2008 Myanmar Nargis kasırgas1, 2008 Sichuan depremi, 2010 Rusya 1s1 dalgas1, 2010 Haiti depremi, 2010 Rio de Janeiro selleri ve çamur kaymaları, 2012 süper kum firtınası, 2017 Harvey ve Irma kasırgası, 2018 Kerala seli vs gibi can ve mal kaybina neden olan etkili afetler yaşanmıştır. Christian Aid'e göre, önümüzdeki 40 yll boyunca, 25 milyon ile 1 milyar arasında insanın, iklim kaynaklı nedenlerle göç edeceğini tahmin edilmektedir. Ayrıca iklim değişikliği etkilerinden dolayı 1 milyar insanın yer değiştirmesi beklenmektedir (Christian Aid, 2007). Dünya Bankasının “Groundswell” iç göç raporuna göre, "kötümser" (pessimistic), "daha kapsayı1 kalkınma" (more inclusive development) ve "daha iklim dostu" (more climate friendly) olmak üzere 3 farklı senaryo ön görülmüştür. Sahra altı Afrika, Güney Asya ve Latin Amerika'da 2050 yılına kadar iç göçün artacağını tahmin edilmektedir. "Kötümser" senaryoya göre ise, Sahra altı Afrika'da yaklaşık 86 milyon, Güney Asya'da 40 milyon ve Latin Amerika'da göç eden insan sayısının 17 milyon olacağı düşünülmektedir (World Bank, 2018). Bu senaryoda en kırılgan ve dirençsiz insanlar fakir insanlar ve ülkeler ise en fakir ülkelerdir. İç göçmenlerin önemli bir kısmının yakındaki büyük şehirlere ve başkentlere göç ettiği görülmüştür. En az gelişmiş, daha az gelişmiş ve gelişmiş ülkelerin sırasıyla yüzde 32, yüzde 41 ve yüzde 78'inin kentsel alanlarda yaşadığ1 görülmektedir (UNDESA, 2018).

2016 yılına ait Küresel Risk Algılama Anketine göre önümüzdeki 10 yıl boyunca en etkili 10 riskten 3’ünün çevresel riskler olduğu değerlendirilmiştir. Bunlar su krizleri, iklim değişikliğine adaptasyonunun başarısızlığ1 ve biyolojik çeşitlilik kaybıdır [Bündnis Entwicklung Hilft ve United Nations University - Institute for
Environment and Human Security (UNU-EHS), 2016]. Anket, kontrolsüz nüfus göçlerinin gerçekleşeceğini de göstermektedir. 2014 yllında, çevre/iklim ya da çatışma (savaş, terör vb.) ile ilgili nedenlerden dolayı göçmen sayısı II. Dünya Savaşı'ndan bu yana en yüksek seviyesine ulaşmıştır. İyileştirmenin başarısız olduğu ve adaptasyon sorununun son birkaç y1l içerisinde küresel riski arttırdığ1 açıktır. 2016 yılında, iklim değişikliği etkilerinin azaltılması ve uyumun başarısızlığ risk açısından ilk sırada yer almaktadır ve aşırı hava olayları ise 2018 yılında ilk sırada yer almıştır. Su temini krizi ise, 2012-2013 y1lları için ikinci sırada (su temini toplumsal bir risk olarak sınıflandırılmakta ve çevre ile ilişkili kabul edilmektedir), 2014 ve 2017 y1lında ise üçüncü sırada yer almıştır. Tablo 1'de, küresel risk raporuna göre çevresel etki ve göç durumu tablosu sunulmuştur.

\section{Gelişmiş ve gelişmekte olan ülkelerde çevreden kaynaklanan göçün nedeni}

Yukarıda bahsedilen çevreden kaynaklanan göçün büyüklügü ve ortaya çıkma nedeninin pek çok boyutu vardır. Ekonomik, sosyal ya da çevresel boyutlar bazen tek başına, bazen de aynı anda etkili olabilmektedir. Ekonomik, sosyal ya da çevresel faktörlerin bazen birbiriyle birleşme ya da çakışma eğiliminde olduğu gri bölgeler vardır. Göç Enstitüsü, umutların tükendiği, toplumun her kesiminde yaygin olarak görülen bir "devrilme-yıkılma noktası" olduğunu belirtmektedir. Bu noktaya gelindiğinde insanlar kalmaktan ziyade, yer değiştirmeye karar verirler (IOM, 2009; Leutz, 2013). $\mathrm{Bu}$ eşik değere geldiğinde, insanlar harekete geçmeye karar verirler (IOM, 2009; Leutz, 2013). Dolaysiyla, IOM çevreden kaynaklanan göçün çok kutuplu bir durum olduğunu belirtmektedir (IOM, 2009). Halk, 
çeşitli nedenlerden dolayı bir yerden başka yere hareket etmektedir ve insanların yer değiştirmeleri birden fazla sebebe bağlıdır. Hareket hem doğrudan hem de dolaylı etkilerden kaynaklanmaktadır. Çevreden kaynaklanan insan göçünün nedenleri hem çevresel olan hem de çevresel olmayan nedenlerle ilişkilendirebilmektedir (IOM, 2008). Lonergan (1998), yer değiştirme veya yeniden yerleşime neden olan en s1k bahsedilen çevresel nedenleri beş genel grupta (doğa kökenli afetler, yavaş gelişen afetler, endüstriyel kazalar, kalkınma projeleri, ve çatışmalar-savaşlar) tanımlamıştır. Çevresel olmayan nedenler ise hızlı kentleşme, ekonomik sıkıntı, yetersiz eğitim tesisleri, kısıtlı kaynaklar üzerindeki pay çatışmaları, kaynakların eşitsiz dağılımı, kurumsal destek eksikliği, güvenlik kaygısı, suç artışı, siyasi istikrarsızlık, iç savaş, dinî/etnik çatışma, neoliberalizasyon etkisi, başka yerlerde daha iyi firsatlar, salgın hastalıklar, hatalı hükümet politikaları, yönetişim eksikliği olarak sayılabilir ve bu etkiler çevreden kaynaklanan göçün itici faktörlerine katkıda bulunmaktadır. Sorunların ortaya çıkmasında sadece gelişmekte olan ülkeler değil aynı zamanda gelişmiş ülkeler da sorumludur. Bu gibi acil durumlardan, daha çok kırılgan ve uyum kapasitesi yetersiz olan topluluklar etkilenmektedir. Katrina kasırgası sırasında ve sonrasındaki gerçek deneyimler bize azınlıkların ve fakir insanların afet dirençliliğinin daha az olduğunu, dolayisıyla toparlanma kapasitelerinin de düşük olduğunu göstermektedir (Sharkey, 2007).

White (2012), neoliberal politikalar nedeniyle, Kuzey kürede tarımsal ve pastoral ekonomilerde üretimin azaldığını ve bu durumun, Güney Kürede gıda ve/veya fiziksel güvenlik arayan düzensiz göçmenlerin hareketliliğinin artmasına yol açtığını belirtmektedir (White, 2012). Batı dünyasındaki tarımsal ihracat teşvikleriyle ithalat kısıtlamaları, gelişmekte olan ülkelerdeki çevresel yer değiştirmelerin temel nedeni olabilmektedir. Küresel ekonomik kurumlar -IMF, Dünya Bankası ve Dünya Ticaret Örgütü- uluslarüstü hakimiyeti koruyan fikrî mülkiyetin özelleştirilmesini, serbest ticareti ve yatırım ve kontrol koşullarını dayatmaktadır. Kuzeydeki gelişmiş ülkelerin çevre sorunlarından daha fazla sorumlu olduklarını ve gelişmiş ülkeler ile gelişmekte olan ülkeler arasında toplam karbon emisyonu açısından keskin bir fark olduğu da aşikârdır. Örneğin, Amerika Birleşik Devletleri ve Çin'in toplam karbon emisyonu, Bangladeş'inkinin 18 katından daha fazladır. Ortalama olarak bakacak olursak, bir Amerikalının emisyonu kabaca neredeyse beş Çinli ve altmış altı Bangladeşlininkine eşittir (Dryzek vd., 2011).

Uluslararası Stratejik Çalışmalar Enstitüsü'ne göre (International Institute for Strategic Studies - IISS), kırılgan ülkelerde kısa vadede iklim değişikliklerinden kaynaklanan göçte artış görülecektir (IISS, 2011). Alman Küresel Değişiklikler Tavsiye Konseyi (German
Advisory Council on Global Change) tarafindan yapılan bir araştırmaya göre, uzun vadeli çevresel/iklimsel değişim, büyük ölçekli göç hareketlerini yaratma potansiyeline sahiptir ve daha fakir ülkelerin altyapısı bu durumlara karşı daha az dirençlidir ve uyum kapasiteleri zayıftır. Dolayısıyla, bu konudan kaynaklanacak çatışmaların büyük bir olasılık dâhilinde olduğu görülmektedir (Clark, 2007). 2007 yılında yaşanan, Batı Sudan'daki Darfur iç savaşı, "ilk modern iklim değişikliği çatışmasını”" temsil etmektedir. Eski BM Genel Sekreteri Moon, uzun süren kuraklığın Darfur'daki sorunları tetiklediğine vurgu yapmıştır (Moon, 2007). Çünkü kuraklık, çiftçiler ve çobanların geleneksel varoluş biçimlerini bozmuş ve savaşa katkıda bulunan kıtlığa yol açmıştır.

İklimsel faktörlerin yanı sıra, Yeni Malthuscu düşünürleri nüfus baskısı ve aşırı kaynak tüketiminin de, çatışmaya neden olabileceğini savunmaktadır. Çünkü Yeni Malthuscu yaklaşım, göçün, bir şehrin veya ülkenin nüfus baskısı (örneğin Bangladeş gibi kalabalık ülkeler) için ana tetikleyici etmen olduğunu savunmaktadır. Yoğun nüfus artışı sürdürülebilir üretim için tehdit oluşturmakta ve daha fazla kaynak tüketimine yol açmaktadır. Bu nedenle, kaynak bulmada yaşanan sıkıntılar, kaynaklara ulaşmada rekabeti kızıştıracaktır. Kaynak kazanımı için aşırı mücadele toplulukların çatışmasına dönüşebilmektedir ve bu rekabetin sonucu olarak, zorunlu göçe neden olabilmektedir.

\section{Çevre kaynaklı göç konusunda yapılan uluslararası çalışmalar}

Çevre kaynaklı göçün uluslararası düzeyde meydana getirdiği göç problemine dair günümüze kadar yapılmış olan çalışmalar incelendiğinde, çevresel göçmenlerin mülteci statüsüne ilişkin 1951 Cenevre Sözleşmesi ve 1967 Protokolü kapsamında olmadığ1 görülmektedir. Mülteci hakları üzerine yaygın olarak çalışma yapan BM (Birleşmiş Milletler) kuruluşları, özellikle BM Mülteci Ajansı (UNHCR) ve BM Kalkınma Programı, "iklim mültecisi” teriminin çevresel nedenlerden dolayı yerinden edilmiş kişileri tanımlamak için kullanılmaması gerektiğini düşünmektedir. Aslında 2015 yllında Görev Gücü'nün (Task Force) oluşturulmasının gerekliliğinin dillendirilmesi bu konudaki en önemli adım olarak değerlendirilebilir (UNFCCC, 2016). 2015-2030 Sendai Bildirgesi ve 2015 Paris Anlaşması, sürecin bu konuda ilerleyişine katkı sağlamıştır. 2015-2030 Sendai Bildirgesi, 2015 sonrasındaki gelişmeler içerisindeki ilk büyük adımdır (SKH hedef 11, alt hedef 11b). Birleşmiş Milletler İklim Değişikliği Çerçeve Sözleşmesi'nin (BMIDÇS) 21 Mart 1994'te yürürlüğe girmesine karşın, 2007'ye kadar BMIDÇS anlaşmalarında çevreden kaynaklanan göçle ilgili bir ilerleme kaydedilmemiştir. Ancak BMIDÇS'nin ötesinde bir takım uluslararası ilkesel çalışmalar, eylem planları ve sözleşmeler gibi 
faaliyetler de görülmektedir. En son ulusal hükümetlerin koalisyonu tarafindan 2016 yilinda Afet Kaynaklı Yer değiştirme Platformu'nun (Platform of Disaster Displacement - PDD) yürürlüğe girmesinden sonra büyük ilerleme kaydedilmesi, ülkelerinin bu durumdaki göçmenleri yasal olarak tanınmıyor olmasına rağmen, yardımcı olmalarını teşvik etmektedir (PDD, 2019). Platform, 2015 yılında 109 ülkenin onayladığı ve ilkelerini ulusal yasalara entegre etmeyi amaçlayan bir "Koruma Gündemi” üzerine kurulmuştur (UNFCCC, 2016). PDD'nin etkinliği, BM kuruluşları ile karşılaştırıldığında, yeni küresel yasal standartlar oluşturamadığından dolayı, daha sınırlıdır. Ülke İçinde Yerinden Edilmenin Temel İlkeleri 1998, Kampala Sözleşmesi 2009, Yarımada İlkeleri 2013, Sendai Bildirgesi 2015-2030 çevreden/ iklimden kaynaklanan göç üzerine yapılmış olan bu uluslararası çalışmaların yanı sıra en önemli rolün devlette olduğunu kabul etmektedir.

\section{Sonuç}

İklim değişikliğinin etkileri sonucunda oluşan çevresel değişimlerdenkaynaklanan göç, sadece gelişmekte olan ülkelerde değil, aynı zamanda gelişmiş ülkelerde de yoğun bir şekilde görülmektedir. Bu nedenle, doğa ve insan kaynaklı tehlikeler ve artan zorluklarının üstesinden gelebilmek için hem gelişmiş hem de gelişmekte olan ülkelerde bu sorunların çözümüne ihtiyaç duyulmaktadır. Ancak bu sayede dünyanın güvenli, sürdürebilir ve barışçıl bir ortama dönüştürülmesi mümkün olabilecektir. Gelişmiş ve gelişmekte olan ülkeler arasında coğrafik, iklimsel, sosyo-ekonomik ve demografik olarak birçok farklılıklar vardır. Ancak çevreden kaynaklanan göç sorunlarını çözmek için herkesin çaba sarf etmesi gerekmektedir. Bu yüzden aşağıdaki öneriler hem gelişmiş hem de gelişmekte olan ülkelere yönlendirme sağlaması açısında önemli görülmektedir.

\section{Gelişmiş ülkeler için:}

- Gelişmiş ülkelerin, yerlerinden edilmiş kişiler için geçici ve kalıcı olarak büyük sorumluluk almaları gerekmektedir. Bu sebeple, gerek iç göç gerekse dış göç ile ilgili olarak tüm gelişmiş ülkeler BM sözleşmelerine ve anlaşmalarına katılmalı ve imzalamalıdır.

- Gelişmiş ülkeler, ekonomik büyüme, yeterli bütçe ve direnç-odaklı uygulamalar sağlamalarının yanı sıra, çevreden kaynaklanan göçe eğilimli olanlar (motive edilmiş) veya göç etmek zorunda veya göç etmeye zorlanmış göçmenlerin gelecekte korunması için strateji veya eylem planı geliştirmelidir.

Gelişmekte olan ülkeler için:

- Gelişmekte olan ülkelere sadece uyum planlama, eylem planlama değil, aynı zamanda mevzuat hazırlanmas1, yasal mekanizmaların uygulaması gerekmektedir. Çünkü insanların yerlerinden edilmeleri öncesi veya afet sonrasi geri dönenlerin konut, arazi ve mülkünün kabul edilebilir alternatiflerini içeren uygun tazminatın sağlanması gerekmektedir.

- Aralık 2017 itibarıla, gelişmekte olan ülkeler arasından 51 ülke NAPA'larını (National Adaptation Programmes of Action) BM Sekreterliği'ne sunmuştur. Gelişmekte olan ülkeler sadece uyum planı, eylem planı hazırlamakla kalmamalı, aynı zamanda çevreden kaynaklanan göç ülkenin bir sorunu olarak kapsamlı şekilde değerlendirilmeli ve sıcak nokta alanlarında yeterli uyum projelerinin yanı sıra plansız kentleşmenin olumsuz etkilerini hafifletici potansiyel çevreden kaynaklanan göçmenlere yönelik politikaların öncelikli olarak yer aldığ1 projeler üretmelerinin gerekliliğ̈i vurgulanmalıdır.

- Tüm gelişmiş ülkeler yoksulluğu azaltmak, geçim koşullarını güvence altına almak ve dirençlilik temelli uygulamaları kapsamlı bir şekilde teşvik etmelidirler.

- Stratejik eylem ve uyum planlamaları süreçlerinin her aşamasına etkilenmiş ya da etkilenmesi olası yerel halkın aktif katılımının sağlanması, gelişmekte olan ülkelerin sağlam ve başarılı bir plan oluşturmasına yardımcı olabilecektir. Bu yüzden planlamalara, yerel ortakların ve toplum odaklı yaklaşımların katılımını yaygin hale getirmek gerekmektedir.

\section{Kaynakça}

Ahsan, M. M. (2017). Role and policy challenges of local governments on environmentally induced displacement and migration in Bangladesh. M. Güler ve M. Turan (ed.) içinde, Belediyelerin Gelecegi ve Yeni Yaklassimlar, 1. Cilt (s. 496-508). Marmara Belediyeler Birliği Kültür Yayınları.

Bettini, G. (2014). Climate migration as an adaption strategy: desecuritizing climate-induced migration or making the unruly governable? Critical Studies on Security, 2(2). https://doi.org/10 $.1080 / 21624887.2014 .909225$

Bündnis Entwicklung Hilft ve United Nations University - Institute for Environment and Human Security (UNU-EHS) (2016). World Risk Report 2016, Germany.

Clark, W. (2007). Environmentally induced migration and conflict. German Advisory Council on Global Change (WBGU), Germany.

Council of Europe (2008). Environmentally induced migration and displacement: A 21 st century challenge. https://www.refworld.org/ docid/49997bbb0.html

Christian Aid (2007). Human tide: Real Migration Crisis. London. https://www.christianaid.org.uk/sites/default/ files/2017-08/human-tide-the-real-migration-crisismay-2007.pdf

Davison, S., ve Shire, G. (2015, 13 Şubat). Race, migration and neoliberalism. Open Democracy. https://www.opendemocracy. 
net/ourkingdom/sally-davison-george-shire/race-migrationand-neoliberalism

Dryzek, J. S., Norgaardi R. B., ve Schlosberg, D. (Ed.) (2011). The Oxford handbook of climate change and Society. Oxford University Press.

European Parliament (2011). "Climate Refugees" - Legal and policy responses to environmentally induced migration. https:// www.europarl.europa.eu/RegData/etudes/etudes/ join/2011/462422/IPOL-LIBE ET(2011)462422 EN.pdf

Hayman, R., King, S., Kontinen, T., ve Narayanaswamy, L. (Ed.) (2016). Negotiating knowledge: Evidence and experience in development NGOs. Practical Action Publishing. https://doi. org/10.3362/9781780449258.009

IDMC - Internal Displacement Monitoring Centre (2016). Global report on internal displacement. Geneva: Internal Displacement Monitoring Centre. https://www.internal-displacement.org/ sites/default/files/publications/documents/2016-globalreport-internal-displacement-IDMC.pdf

IOM - International Organisation for Migration (2007). Discussion note: Migration and the environment (MC/INF/2008). International Organization for Migration. https://www.iom. int/jahia/webdav/shared/shared/mainsite/about iom/en/ council/94/MC INF 288.pdf

IOM - International Organisation for Migration (2008). World migration 2008: Managing labour mobility in the evolving global economy. Volume 4 - IOM World Migration Report Series. Switzerland. https://publications.iom.int/system/files/pdf/ wmr 1.pdf

IOM - International Organisation for Migration (2009). Migration, environment and climate change: Assessing the evidence. https:// publications.iom.int/system/files/pdf/migration and environment.pdf

IISS - International Institute for Strategic Studies (2011). The IISS transatlantic dialogue on climate change and security. http://www. andrew-holland.com/uploads/6/3/1/7/6317360/climate change security final report.pdf

Leutz, J. (2013). Climate migration: preparedness informed policy opportunities identified during field research in Bolivia, Bangladesh, and Maldives. Yayımlanmamış Doktora Tezi. The Univeristy of New South Wales, Avustralya.

PDD - Platform of Disaster Displacement (2019). Platform on disaster displacement (PDD) strategy 2019. 2022. $\quad$ https://disasterdisplacement.org/wp-content/ uploads/2019/06/26062019-PDD-Strategy-2019-2022FINAL to post on website.pdf

McAdam, J. (2016). From the nansen initiative to the platform on disaster displacement: Shaping international approaches to climate change, disasters and displacement. UNSW Law Journal, 39(4), 1518-1546. https://doi.org/10.2139/ $\underline{\operatorname{ssrn} .2901910}$

Moon, B. K. (2007, 16 Haziran). A climate culprit in Darfur. The Wasginton Post. https://www.washingtonpost.com/wp-dyn/ content/article/2007/06/15/AR2007061501857.html

Sassen, S. (2014). Expulsions: Brutality and complexity in the global economy. Harvard University Press.

UNDESA - United Nations Department of Economic and Social Affairs (2018). World urbanization prospects: The 2018 revision. (ST/ESA/SER.A/420). United Nations. https://population. un.org/wup/Publications/Files/WUP2018-Report.pdf

UNFCCC - United Nations Framework Convention on Climate Change (2016). Report of the conference of the parties on its twentyfirst session, held in Paris from 30 November to 13 December 2015. Part one: Proceedings. (FCCC/CP/2015/10). http://unfccc.int/ resource/docs/2015/cop21/eng/10.pdf

UNISDR - United Nations Office of Disaster Risk Reduction (2015). Sendai framework for disaster risk reduction 2015 - 2030. The United Nations Office for Disaster Risk Reduction, Geneva, Switzerland. https://www.preventionweb.net/ files/43291 sendaiframeworkfordrren.pdf

UNOCHA - United Nations Office for the Coordination of Humanitarian Affairs (2004). Guiding principles on internal displacement. United Nations.

UNHCR - United Nations High Commissioner for Refugees (2017). Climate change and disaster displacement: An overview of UNHCR's role. UNHCR, Switzerland. https://www.unhcr. $\mathrm{org} / \mathrm{protection} /$ environment/5975e $6 \mathrm{cf} 7 /$ climate-changedisaster-displacement-overview-unhcrs-role.html

Varol, N., ve Gültekin, T. (2016). Etkin bir göç faktörü: Afetler. Antropoloji, 32, 43-51. https://doi.org/10.1501/ antro 0000000337

Waldinger, M., ve Fankhauser, S. (2015). Climate change and migration in developing countries: evidence and implications for PRISE countries. Centre for Climate Change Economics and Policy (CCCEP).

White, R. (Ed.) (2012). Climate change from a criminological perspective. Springer. https://doi.org/10.1007/978-1-4614$\underline{3640-9}$

World Bank (2018). Groundswell: Preparing for internal climate migration. International Bank for Reconstruction and Development / The World Bank. https://openknowledge.worldbank.org/ bitstream/handle/10986/29461/WBG ClimateChange Final.pdf

World Economic Forum (2018). The global risks report 2018, 13th edition. World Economic Forum. http://www3.weforum.org/ docs/WEF GRR18 Report.pdf

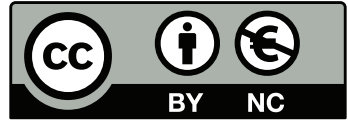

2020. Telif haklar1 yazar(lar)a aittir.

Bu makale Creative Commons Atıf-GayriTicari 4.0 Uluslararas1 (CC BY-NC 4.0) lisansının hüküm ve şartları altında yayımlanan açık erişimli bir makaledir. 